Article

\title{
Influence of AlN Nanoparticle Addition on Microstructure and Mechanical Properties of Extruded Pure Magnesium and an Aluminum-Free Mg-Zn-Y Alloy
}

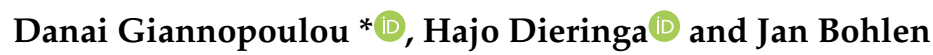 \\ MagIC-Magnesium Innovation Centre, Institute of Materials Research, Helmholtz-Zentrum Geesthacht, \\ Max-Planck-Str. 1, 21502 Geesthacht, Germany; hajo.dieringa@hzg.de (H.D.); jan.bohlen@hzg.de (J.B.) \\ * Correspondence: danai.giannopoulou@hzg.de; Tel.: +49-4152-872399
}

Received: 21 May 2019; Accepted: 6 June 2019; Published: 8 June 2019

\begin{abstract}
A pure Mg and a ZW0303 alloy metal matrix nanocomposite reinforced with AlN nanoparticles were prepared assisted by mechanical stirring and sonication for deagglomeration of particles. The produced nanocomposites were investigated to determine the influence of the AlN nanoparticles during indirect extrusion on the microstructure and texture development, as well as the resulting hardness and mechanical properties. For pure $\mathrm{Mg}$, grain refinement and hardness increase due to the addition of AlN were revealed in the as-cast and the extruded condition. For ZW0303, the same was found for the as-cast condition. However, contamination of the alloy with Al significantly changes the recrystallization behavior during extrusion. This is directly related to the removal of solute $\mathrm{Y}$ due to the formation of intermetallic particles. Particle and grain size effects were distinguished for this alloy.
\end{abstract}

Keywords: nanoparticles; metal matrix nanocomposite MMNC; AlN; magnesium Alloy ZW0303; extrusion

\section{Introduction}

Nanocomposites with a magnesium matrix have been a major focus of interest in lightweight construction for several years. In an environment where the price of ceramic nanoparticles has decreased significantly in recent years, the specific strength, which is already relatively high for magnesium alloys, can be further increased. The addition of microscale particles typically leads to an increase in strength with a simultaneous decrease in ductility. Moreover, the density increases significantly at a volume content of 10-30\%, which in turn has a negative effect on the specific strength. However, nanoscale particles can already achieve their strength-increasing effect at low concentrations of $0.5-3 \%$. This is due to mechanisms such as Orowan strengthening or subsequent grain refinement. Some review articles describe the properties and manufacturing methods of metal matrix nanocomposites (MMNCs) [1-5].

In comparison to microscale particles, the homogeneous distribution of nanoparticles is a major challenge. Due to their large surface area, the van der Waals forces between the particles are large. They are therefore more difficult to deagglomerate. In addition, the wettability of many ceramic particles with a molten metal is poor. If the surface to be wetted increases, this effect becomes even more apparent. This challenge can usually only be met by using additional physical forces, which have to be applied during casting. An ultrasound assistance can be applied, or electromagnetic stirring can be used. Intensive shearing or a disintegrated melt deposition (DMD) process are also already in use. After being stirred into the melt and the casting, the question arises whether further homogenization 
of the nanoparticle distribution can be achieved in the subsequent extrusion process. In this work, ultrasound-assisted casting was chosen to deagglomerate the particles in the melt. This has, for example, been shown to be successful in [6], where the yield strength in an AIN nanoparticle-reinforced AM60 magnesium alloy could be increased from 45 to $92 \mathrm{MPa}$ and the tensile strength from 109 to $235 \mathrm{MPa}$, thus more than $100 \%$, respectively. The ductility could even be increased by $140 \%$ in the cast state by grain refinement from $1277 \mu \mathrm{m}$ to $85 \mu \mathrm{m}$. Following the known models, a small proportion of the increase in the yield strength of $12 \mathrm{MPa}$ could be explained by the Orowan mechanism, while the predominant $43 \mathrm{MPa}$ could be attributed to grain refinement. The deviation of the sum of the simulated increase from the increase determined experimentally has been explained by a remaining non-homogeneous distribution of the particles. Thus, the homogenization of the material remains an issue.

The property development during the extrusion of profiles as a massive deformation process is to a large extent based on the microstructure development as a result of recrystallization. Typically, finer-grained microstructures after extrusion allow enhancing both strength and ductility of the material $[7,8]$.

Extrusion includes stress conditions which lead to a macroscopic change of the material such as the transition from billet to profile and translate the same changes into the microstructure. This includes resulting tensile stresses parallel to the extrusion direction (ED) or effective compressive stresses perpendicular to ED. Thus, unrecrystallized grains after extrusion occur as large long grains with their long extension parallel to the extrusion direction [9]. The same is visible if undissolved particles of intermetallic compounds persist in the microstructure during extrusion, leading to stringer-like lines of such inclusions parallel to the extrusion direction [9]. Only grains which underwent recrystallization occur with an equi-axed type, and only particles that may have formed during extrusion, for example, as a result of a process related to precipitation are typically homogeneously distributed. It remains an open question if dispersoid particles like nanoparticles can effectively and directly act as a strengthener of the material if tested parallel to ED. Furthermore, a particle-related impact on the microstructure, for example, the grain size, is likely to have an impact on the mechanical properties.

As an example, after hot extrusion in an AZ91, which was reinforced with 1 vol.\% $60 \mathrm{~nm} \mathrm{SiC}$ particles, the local areas with higher nanoparticle concentrations reveal smaller grains than in the areas with fewer nanoparticles [10]. Then the tensile yield strength as well as ultimate tensile strength is increased compared to unreinforced extruded AZ91, whereas the ductility is slightly reduced. An Mg-4Zn-3Gd-1Ca alloy was produced with 2 wt.\% ZnO nanoparticles with a size of 90-200 nm using the DMD process and then extruded at $300{ }^{\circ} \mathrm{C}$ [11]. The compressive yield strength could be increased by about $100 \mathrm{MPa}$ to $355 \mathrm{MPa}$ and the compressive strength even by $120 \mathrm{MPa}$ to $703 \mathrm{MPa}$. At the same time, the ductility decreased only slightly from $12.6 \%$ to $10.6 \%$. The main reason for the increase in strength is seen in the grain refinement by the nanoparticles. The grain size in the nanocomposite was $0.91 \mu \mathrm{m}$ and in the unreinforced alloy $1.42 \mu \mathrm{m}$.

Non-particle related alloying effects during extrusion include changes in the dominant deformation and recrystallization mechanisms, which are based on changes in the texture development [12]. Alloying with rare earth or yttrium has been used as a texture modifier to especially promote ductility [13]. An additional increase in the strength properties is then assumed due to the addition of nanoparticles.

In this work, AlN nanoparticles are used and distributed during casting into pure $\mathrm{Mg}$ as a benchmark as well as into a $\mathrm{Mg}$-Zn-Y-containing alloy, known for its texture modifications during extrusion [13-15]. The microstructure and hardness response of the material after casting is compared to the respective counterparts after extrusion. The extrusion behavior is specifically investigated, and the microstructure and texture development are reviewed. The mechanical properties are related to the respective microstructures. 


\section{Materials and Methods}

\subsection{Casting}

Pure Mg and a ZW0303 alloy (composition in wt.\%: Mg-0.3Zn-0.3Y) were melted at $750{ }^{\circ} \mathrm{C}$ and poured into a preheated mold $\left(450^{\circ} \mathrm{C}\right)$. The cylindrical mold was put into a three-zone resistance furnace (ThermConcept, Bremen, Germany) to maintain the temperature of the melt at $720^{\circ} \mathrm{C}$. Each casting was carried out either without the addition of particles as a base material or with addition of AlN particles. AlN nanoparticles had a mean diameter of $80 \mathrm{~nm}$ (produced by Tomsk State University, Russia). Details on the AlN powder and its production can be found in [16]. However, they consisted not only of pure AlN but also of about $25 \% \mathrm{Al}$ nanoparticles due to the production process. After creating a vortex by mechanical stirring $(200 \mathrm{rpm})$, the AlN nanoparticles were added to the melt. Three different amounts of nanoparticles were used to vary the content of the reinforcement. Although AlN has a density of $3.26 \mathrm{~g} / \mathrm{cm}^{3}$, the powder used was much more voluminous due to its manufacturing process. The measured density of the freely poured powder is only $0.174 \mathrm{~g} / \mathrm{cm}^{3}$. This large volume makes stirring even small quantities, such as $1 \%$ by weight, very demanding. Table 1 summarizes the composition of the alloy and the content of AlN nanoparticles. Both the theoretical volume content calculated from the true density and the volume content calculated from the poured volume are given. Ultrasonic stirring was applied for $5 \mathrm{~min}$ at $0.3 \mathrm{~kW} / 20 \mathrm{kHz}$ in order to disperse the particle clusters. Then, the mold with the melt was lowered into a water bath underneath the furnace at a constant speed of $3 \mathrm{~mm} / \mathrm{s}$. Therefore, solidification was initiated at the bottom of the mold, and directional solidification was realized. This process produces very dense castings because the remaining melt is always above the solid-liquid interface, which leads to shrinkage feeding.

Table 1. Sample labelling and content of AlN in the materials.

\begin{tabular}{ccccc}
\hline Material & Alloy Composition (wt.\%) & $\begin{array}{c}\text { AlN } \\
\text { (wt.\%) }\end{array}$ & $\begin{array}{c}\text { AlN } \\
\text { (theor. vol.\%) }\end{array}$ & $\begin{array}{c}\text { AlN (vol.\%) } \\
\text { Poured Volume }\end{array}$ \\
\hline $\begin{array}{c}\text { Mg } \\
\text { Mg + 0.75AlN }\end{array}$ & $99.97 \mathrm{Mg} ; 0.01 \mathrm{Al} ; 0.002 \mathrm{Ce} ;$ & - & - & - \\
$\mathrm{Mg}+1.0 \mathrm{AlN}$ & $0.004 \mathrm{Fe}$; 0.004 Mn; 0.004 Si; & 0.86 & 0.46 & 8.4 \\
$\mathrm{Mg}+1.5 \mathrm{AlN}$ & $0.003 \mathrm{Zn}$ & 1.18 & 0.63 & 11.8 \\
\hline ZW0303 & & - & 0.95 & 17.8 \\
ZW0303 + 0.75AlN & $99.3 \mathrm{Mg} ; 0.28 \mathrm{Zn} ; 0.26 \mathrm{Y} ;$ & 0.80 & - & - \\
ZW0303 + 1.0AlN & $0.02 \mathrm{Mn} ; 0.01 \mathrm{Al} ;$ & 1.09 & 0.53 & 10.9 \\
ZW0303 + 1.5AlN & & 1.58 & 0.84 & 15.8 \\
\hline
\end{tabular}

\subsection{Extrusion}

Four billets of $\mathrm{Mg}$ and ZW0303, respectively, were machined from the castings with a diameter of $48 \mathrm{~mm}$ to fit the $50 \mathrm{~mm}$ diameter of the extrusion press. The billet length varied slightly between 127 and $135 \mathrm{~mm}$. A homogenization heat treatment of $16 \mathrm{~h}$ at $400{ }^{\circ} \mathrm{C}$ was carried out, followed by air-cooling. Indirect extrusion was carried out at $300{ }^{\circ} \mathrm{C}$ using an extrusion speed of $2.2 \mathrm{~mm} / \mathrm{s}$ to produce round bars with a diameter of $10 \mathrm{~mm}$. This results in an extrusion ratio of 1:25 and a profile exit speed of $3.3 \mathrm{~m} / \mathrm{min}$. After exiting the die, the profiles were cooled down in air to room temperature.

\subsection{Microstructure and Mechanical Characterization}

A microstructural analysis was carried out by using optical microscopy on longitudinal sections of the profiles. Samples were cut from the resulting bars. Each sample was embedded in resin, ground (SiC papers: 500, 800, 1200, 2500), polished $(0.25 \mu \mathrm{m}$ diamond paste in oxide polishing suspension, and etched (9\% picric acid solution). The average grain size was determined using a computer-aided linear intercept measurement. Electro-chemical polishing with acetic acid for $30 \mathrm{~s}$ (Struers GmbH, LectroPol-5, Willich, Germany) was carried out for energy-dispersive X-ray spectroscopy analysis (EDX) using a 
field emission gun scanning electron microscope (SEM) (Carl Zeiss AG, Ultra 55, Oberkochen, Germany) in order to reveal the chemical composition of the particles formed during casting. A Panalytical ${ }^{\mathrm{TM}}$ (Almelo, The Netherlands) X-ray goniometer setup for texture measurements using $\mathrm{Cu}-\mathrm{K} \alpha$ radiation in reflection geometry was used to measure six pole figures to a tilt angle of $70^{\circ}$ on cross-sections of the extruded bars. The data were used to calculate the complete orientation distribution functions, which allows the recalculation and presentation of complete inverse pole figures by applying the open access code MTEX [17].

Vickers hardness tests HV5 were performed with an EMCO test machine using an indentation load of $5 \mathrm{~kg}$. The hardness results presented are the average of 10 measurements for each sample. Mechanical tests were conducted on the extruded samples. Tensile samples were machined to a gauge length of $30 \mathrm{~mm}$ and a diameter of $5 \mathrm{~mm}$, while the samples for compression had a length of $13.5 \mathrm{~mm}$ and a diameter of $9 \mathrm{~mm}$. Both tests were conducted at room temperature and at a constant strain rate of $10^{-3} \mathrm{~s}^{-1}$ with a universal testing machine (Zwick ${ }^{\mathrm{TM}} \mathrm{Z050}$, Ulm, Germany).

\section{Results and Discussion}

\subsection{Microstructure}

Figure 1 shows the microstructures of the samples of all investigated materials in the as-cast state. Figure $1 \mathrm{a}$ represents the pure magnesium and Figure $1 \mathrm{~b}-\mathrm{d}$ the nanocomposites with $0.75,1$, and 1.5 wt.\% AlN added. Although the content of particles is very low, the images seem to show a high volume content. This is due to etching, which also removes areas around the particles or agglomerates, giving the impression that the particle content is significantly higher.

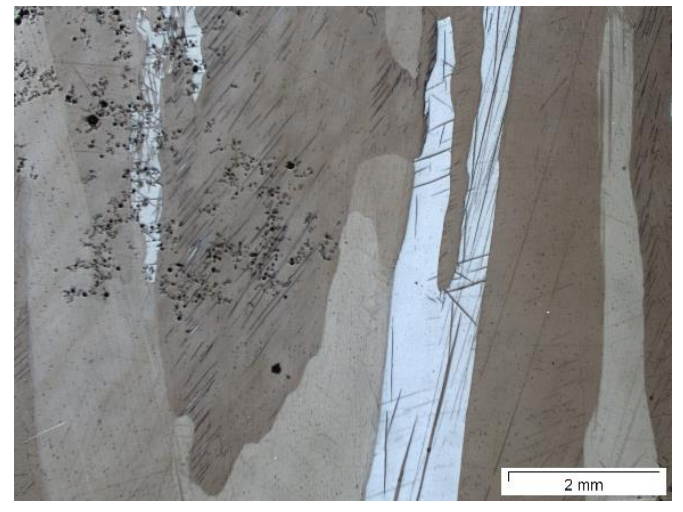

(a)



(c)

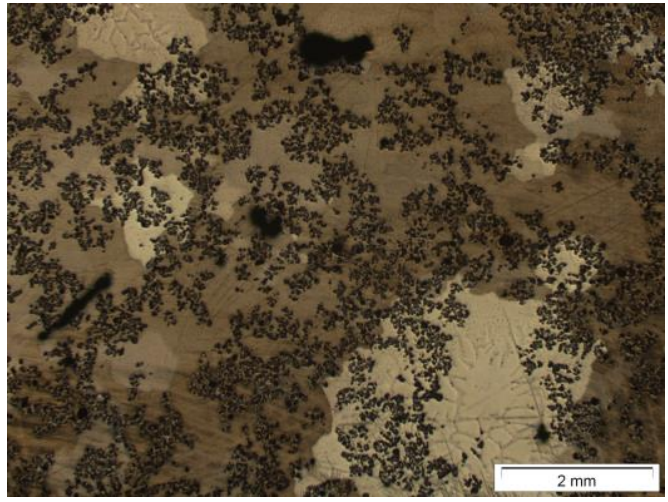

(b)



(d)

Figure 1. Cont. 


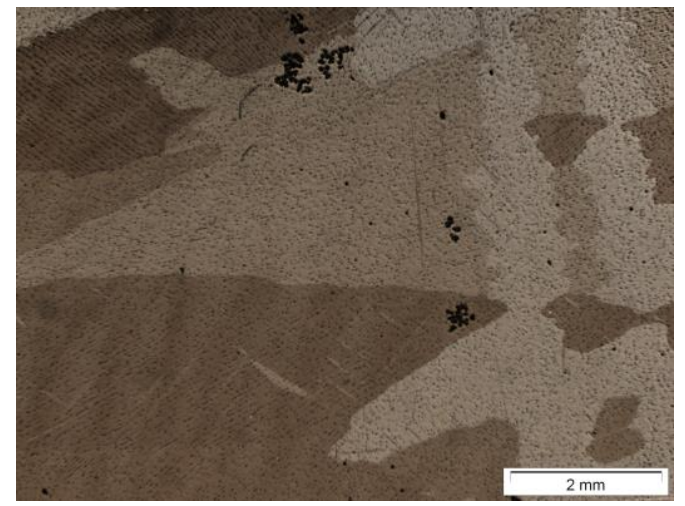

(e)



(g)

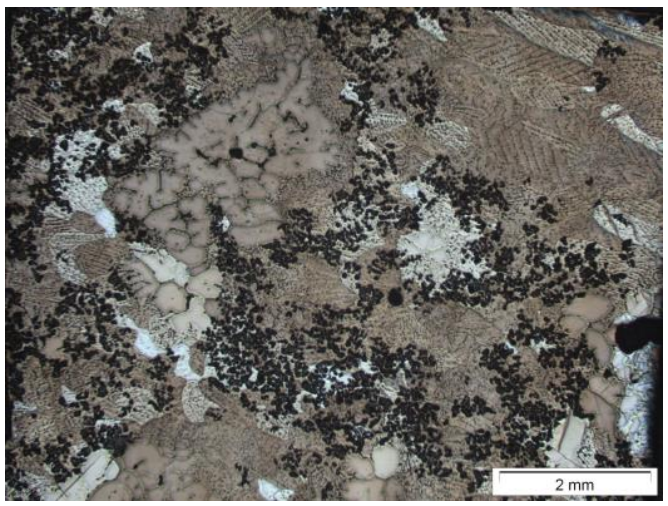

(f)

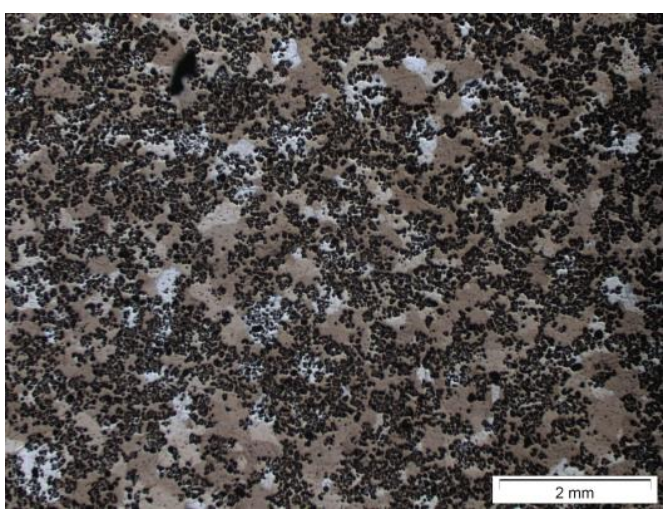

(h)

Figure 1. As-cast microstructures of pure Mg with (a) 0 , (b) 0.75 , (c) 1.0, and (d) $0.5 \mathrm{AlN}$ and ZW0303 with (e) 0 , (f) 0.75, (g) 1.0 , and (h) $1.5 \mathrm{AlN}$.

The very large grains and the large area of the etched surface around the particles prevents a quantitative analysis of the average grain size in these cast conditions. However, from Figure 1a-d, the qualitative impression is revealed that the microstructure remains finer grained with a higher AlN content. Figure 1e-h shows the same results for the ZW0303-based materials. The same grain-refining tendency is also revealed in this alloy with increasing AlN nanoparticle content.

The SEM images and EDX analysis in Figure 2a show the composite material consisting of pure magnesium with $1.5 \%$ AlN nanoparticles with a particle agglomerate of AlN nanoparticles and their composition in the matrix, and the composition of the matrix itself. Some solute $\mathrm{Al}$ in the matrix is also revealed. Figure $2 \mathrm{~b}$ shows the matrix and its composition of alloy ZW0303, zinc, and yttrium are present as alloying elements in solid solution, and an yttrium-rich particle (P2) appears as well. The ZW0303 reinforced with 1.5\% AlN nanoparticles is shown in Figure 2c. An yttrium-rich particle, agglomerates of AlN, and the fact that the matrix alloy ZW0303 is free of yttrium in the analysis are noticeable (see Figure 2c). 




(a)

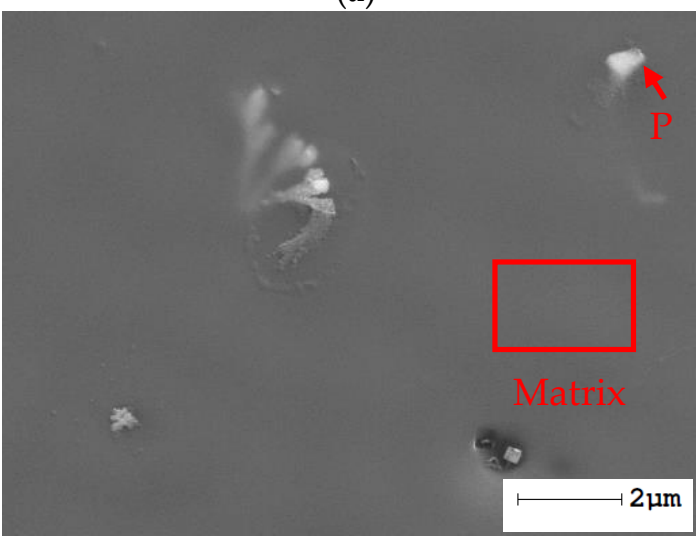

(b)



\begin{tabular}{ccc} 
& & \\
& & \\
\hline Elements & P3 [wt.\%] & Matrix [wt.\%] \\
\hline $\mathrm{Mg}$ & 76.4 & 99.1 \\
$\mathrm{Al}$ & 0.4 & - \\
$\mathrm{N}$ & 1.4 & - \\
$\mathrm{O}$ & 3 & 0.2 \\
$\mathrm{Y}$ & 18 & - \\
$\mathrm{Zn}$ & 0.5 & 0.4 \\
\hline
\end{tabular}

\begin{tabular}{ccc} 
& & \\
& & \\
\hline Elements & P2 [wt.\%] & Matrix [wt.\%] \\
\hline Mg & 73.5 & 98.8 \\
$\mathrm{Al}$ & - & - \\
$\mathrm{N}$ & - & - \\
$\mathrm{O}$ & 0.8 & 0.2 \\
$\mathrm{Y}$ & 17.4 & 0.2 \\
$\mathrm{Zn}$ & 1 & 0.7 \\
\hline
\end{tabular}

\begin{tabular}{ccc}
\hline Elements & P1 [wt.\%] & Matrix [wt.\%] \\
\hline $\mathrm{Mg}$ & 75.5 & 98.5 \\
$\mathrm{Al}$ & 8.2 & 1 \\
$\mathrm{~N}$ & 5.6 & - \\
$\mathrm{O}$ & 10.4 & 0.3 \\
\hline
\end{tabular}

(c)

Figure 2. SEM micrographs and EDX analysis of (a) Mg + 1.5AlN, (b) ZW0303, and (c) ZW0303 + $1.5 \mathrm{AlN}$.

Figures 3 and 4 collect the micrographs of both material series after extrusion and the average grain size as a function of AlN nanoparticle content, respectively. The samples with added AlN nanoparticles revealed structures of horizontal alignments from particle stringers which was more visible if the AlN content was higher. Pure Mg (Figure 3a) exhibited a homogeneous and fine-grained microstructure. With the addition of the AlN nanoparticles (Figure 3b-d), the grains became gradually and slightly finer than in pure $\mathrm{Mg}$, and specifically the areas with the existence of nanoparticles revealed even smaller grains. In the case of pure ZW0303 alloy (Figure 3e), a very fine-grained microstructure was the result. Nevertheless, the counterparts with added AlN nanoparticles (Figure $3 \mathrm{f}-\mathrm{h}$ ) remained significantly coarser grained. 




(a)

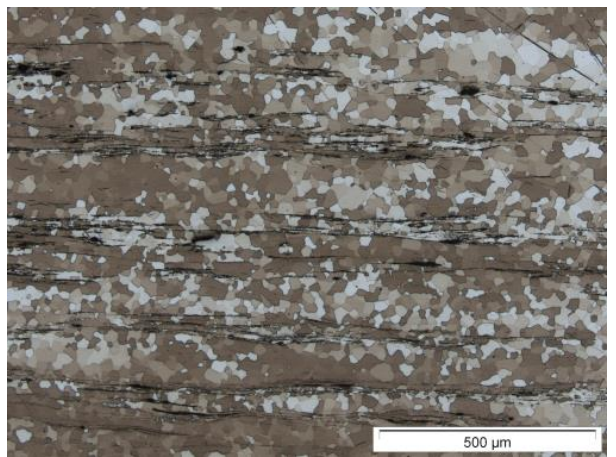

(c)



(e)



(g)



(b)

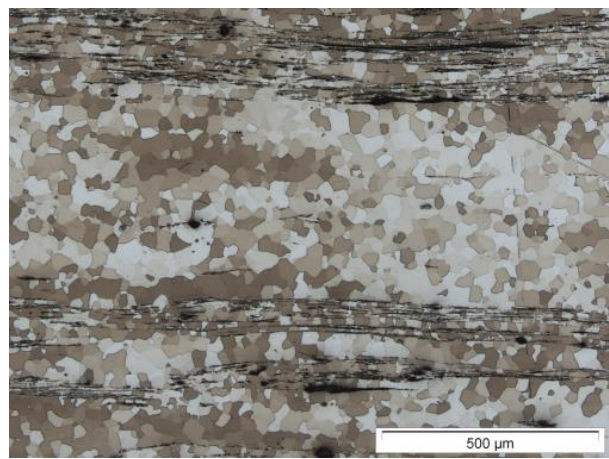

(d)



(f)

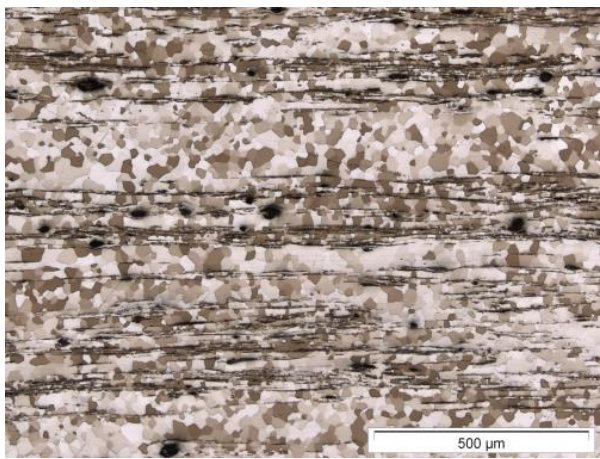

(h)

Figure 3. Microstructures from longitudinal sections (extrusion direction $\rightarrow$ ) of extruded round bars of pure $\mathrm{Mg}$ with (a) 0, (b) 0.75, (c) 1.0, and (d) 0.5AlN and ZW0303 with (e) 0, (f) 0.75, (g) 1.0, and (h) $1.5 \mathrm{AlN}$. 


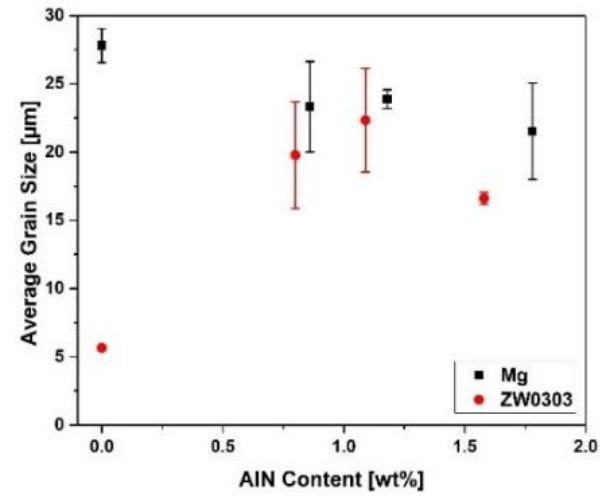

Figure 4. Average grain size values of extruded Mg and ZW0303 series.

\subsection{Texture}

Figure 5 illustrates the textures of the extruded round bars in the form of inverse pole figures in the extrusion direction (ED). Figure 5a for pure $\mathrm{Mg}$ shows a typical texture for a $\mathrm{Mg}$ extrusion with the highest intensities along the arc between the $<10 \overline{1} 0>$ and $<11 \overline{2} 0>$ poles. Thus, basal planes are typically aligned parallel to the extrusion direction. The fact that intensities around the $<11 \overline{2} 0>$ pole were slightly higher compared to those at the $<10 \overline{1} 0>$ pole corresponds well to the recrystallized character of the microstructure [18]. Changes with the addition of AlN (Figure 5b-d) are not distinct.

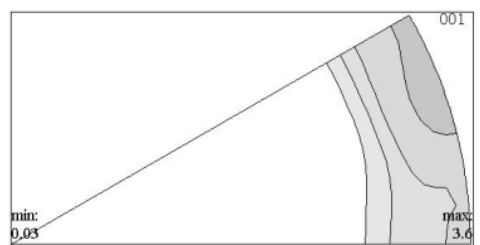

(a)

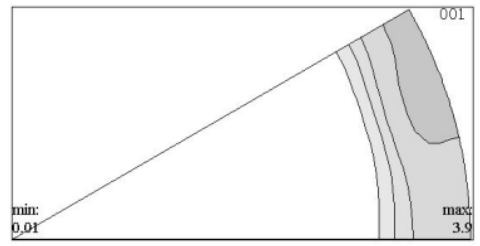

(c)

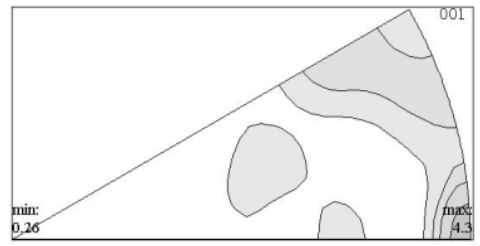

(e)

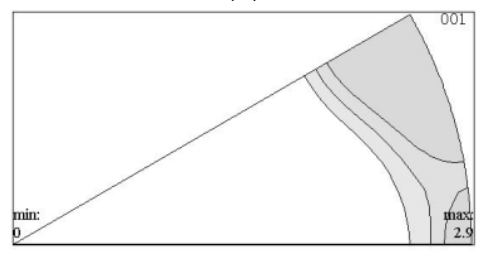

(g)



(b)

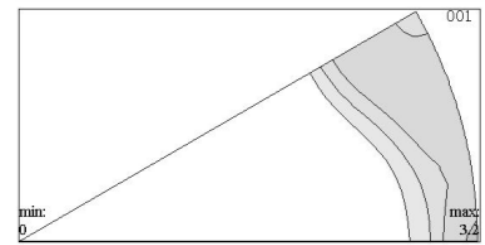

(d)



(f)

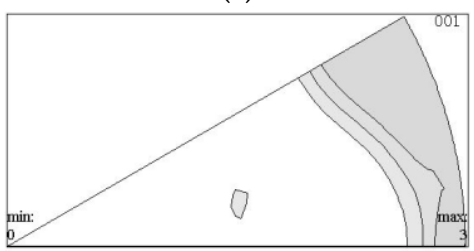

(h)

Figure 5. Inverse pole figures in extrusion direction from extruded round bars, left: $<00 \overline{0} 1\rangle$, bottom right: $<10 \overline{1} 0>$, top right: $<11 \overline{2} 0>$ : (a) $\mathrm{Mg}$, (b) $\mathrm{Mg}+0.75 \mathrm{AlN}$, (c) $\mathrm{Mg}+1.0 \mathrm{AlN}$, (d) $\mathrm{Mg}+1.5 \mathrm{AlN}$, (e) ZW0303, (f) ZW0303 + 0.75AlN, (g) ZW0303 + 1.0AlN, (h) ZW0303 + 1.5AlN. 
For ZW0303, the initial texture of the alloy (Figure 5e) was somewhat different, with the highest intensity at the $<10 \overline{1} 0>$ pole, but other orientations corresponded to a tilt of basal planes out of the extrusion direction. This texture is often found for partly recrystallized microstructures of rare earth-containing alloys $[12,13]$. With the addition of nanoparticles (Figure $5 f-h$ ), the texture remained weaker, but the visible fraction with tilt of basal planes vanished.

\subsection{Mechanical Properties}

Stress-strain diagrams from tensile and compression tests at room temperature are presented in Figure 6, and the mechanical properties are summarized in Table 2. Each curve in Figure 6a-d is a representative selected curve. For each material, the tensile yield stress (TYS) was higher after the addition of AlN nanoparticles.



(a)

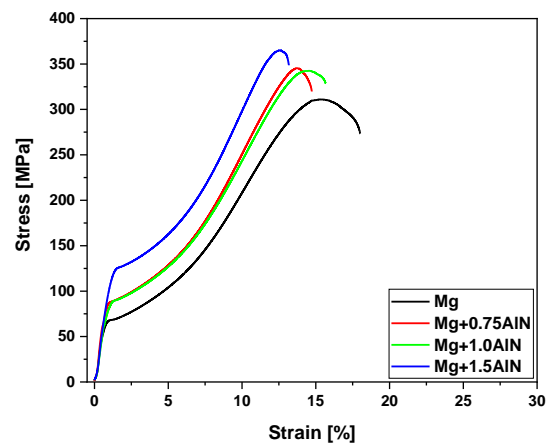

(c)

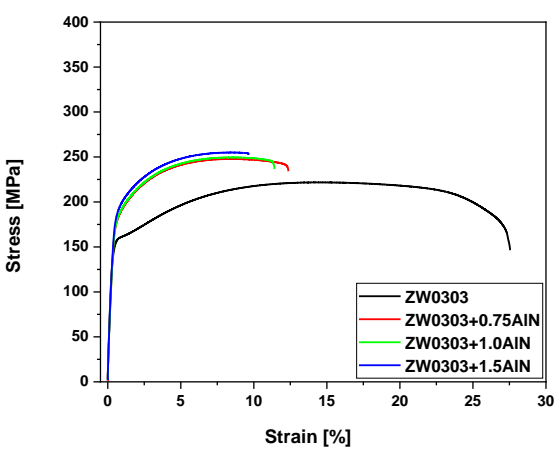

(b)

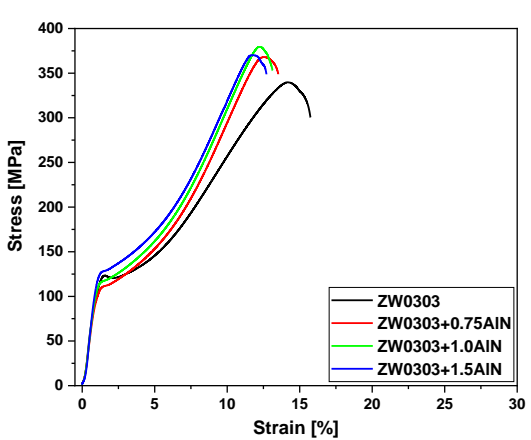

(d)

Figure 6. Stress-strain diagrams of extruded bars of pure Mg-based materials (a,c) and ZW0303-based materials $(\mathbf{b}, \mathbf{d})$ with different contents wt.\% of AlN with respect to tension $(\mathbf{a}, \mathbf{b})$ and compression $(\mathbf{c}, \mathbf{d})$.

Table 2. Results of compression and tensile tests at room temperature. UTS: ultimate tensile strength; TYS: tensile yield strength $(0.2 \%$ proof stress); UCS: ultimate compressive strength; CYS: compressive yield strength $(0.2 \%$ proof stress).

\begin{tabular}{|c|c|c|c|c|c|c|}
\hline Material & TYS [MPa] & UTS [MPa] & $\begin{array}{c}\text { Fracture } \\
\text { Strain [\%] }\end{array}$ & $\begin{array}{c}\text { CYS } \\
\text { [MPa] }\end{array}$ & $\begin{array}{c}\text { UCS } \\
\text { [MPa] }\end{array}$ & $\begin{array}{l}\text { Fracture } \\
\text { Strain [\%] }\end{array}$ \\
\hline $\mathrm{Mg}$ & $101 \pm 4$ & $196 \pm 2$ & $6.9 \pm 0.6$ & $66 \pm 2$ & $314 \pm 2$ & $13.5 \pm 0.2$ \\
\hline $\mathrm{Mg}+1.0 \mathrm{AlN}$ & $124 \pm 2$ & $217 \pm 1$ & $7.6 \pm 0.5$ & $84 \pm 2$ & $337 \pm 4$ & $12.2 \pm 0.2$ \\
\hline $\mathrm{Mg}+1.5 \mathrm{AlN}$ & $159 \pm 3$ & $241 \pm 3$ & $6.6 \pm 0.9$ & $118 \pm 5$ & $365 \pm 5$ & $10.7 \pm 0.1$ \\
\hline ZW0303 & $149 \pm 2$ & $221 \pm 1$ & $16.6 \pm 0.3$ & $118 \pm 7$ & $345 \pm 6$ & $12.4 \pm 0.3$ \\
\hline ZW0303 + 1.5AlN & $177 \pm 2$ & $255 \pm 1$ & $8.6 \pm 0.7$ & $124 \pm 1$ & $372 \pm 1$ & $10.3 \pm 0.1$ \\
\hline
\end{tabular}


For the Mg-based series, $\mathrm{Mg}+1.5 \mathrm{AlN}$ exhibits the highest TYS, ultimate tensile stress (UTS), compressive yield stress (CYS), and ultimate compressive stress (UCS), whereas the lowest values were found for pure $\mathrm{Mg}$ without AlN nanoparticle addition. The addition of the nanoparticles reinforced the Mg samples, but a more ductile behavior was not revealed. A work hardening behavior, that is, the development of the different slope after the yielding point, was not visible for nanocomposites with increasing AlN content, but the curves were pushed to higher stress levels in tension and compression. The CYS, however, was lower than the TYS, which has often been associated with the propensity to twinning being favored in compression (resulting in c-axis extension, as the basal planes are parallel to ED) [19]. No distinct impact on the fracture strain was found in tension and only a slight decrease in compression.

For the ZW0303-based series, again the nanocomposite reinforced with 1.5AlN exhibited the highest TYS, UTS, CYS, and UCS. With increasing addition of AlN, there was again an increase of the resulting stress levels in both directions. However, this development was not of a continuous type. A visible increase in TYS with a small addition of AlN did not increased much more if more AlN was added. At the same time, there was a distinct decrease of the tensile fracture strain. Especially in the tension tests, the strain-hardening slope was also affected. Analyzing the difference between TYS and UTS, the ability to accommodate stress was not changed, that is, $72 \mathrm{MPa}$ for pure ZW0303 and $78 \mathrm{MPa}$ for all nanocomposites based on ZW0303. For the compression tests, the results were comparable. The difference in TYS and UTS was $227 \mathrm{MPa}$ for ZW0303 and 248-262 MPa for the nanocomposites based on ZW0303. The pure alloy ZW0303 exhibited a pronounced elastic limit which was not pronounced after the addition of nanoparticles.

Figure 7 shows the hardness measurements of the Mg and the ZW0303 series as a function of the AlN content for both cast and extruded samples. It appears that $\mathrm{AlN}$ nanoparticles reinforced the $\mathrm{Mg}$ samples to a small extent with a slight increase in the hardness levels. There was no distinct difference between the cast samples and the extruded counterparts despite the differences in the distribution of the particles as well as the grain size. The tendency was also similar to the CYS results in Table 2. Unlike this, in the case of ZW0303 alloy, a drop in the hardness was observed with the addition of the AlN nanoparticles in the first place. Again, this corresponded with the CYS tendency of ZW0303 and its nanocomposites (Table 2). This was followed by an increase again. In comparison, for the cast samples, a continuous increase was found which was slightly more pronounced compared to pure $\mathrm{Mg}$, whereas the extruded samples visibly remained at a higher level.



(a)

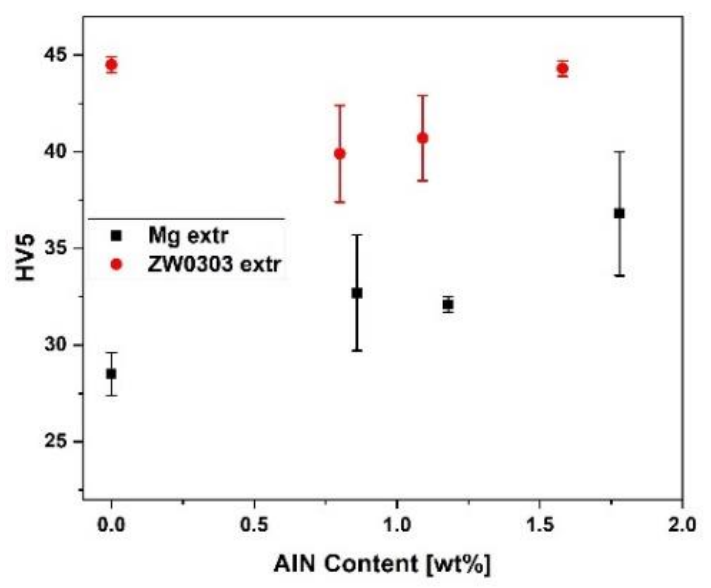

(b)

Figure 7. Hardness of (a) as-cast and (b) extruded Mg and ZW0303 series. 


\section{Discussion}

The increasing content of AlN particles in both as-cast pure Mg and as-cast ZW0303 corresponded directly to an increase in the hardness of the material. This effect was more pronounced in ZW0303 and rather weak in pure $\mathrm{Mg}$. Although the impact of the particle addition on the grain size of the cast samples was not directly revealed, it is also not very likely that an increase of the hardness may be somehow related to a grain size effect in these very coarse grained microstructures. Thus, particle-related strengthening, such as obstacle generation for dislocation motion at the phase boundaries, was considered, whereas the nature of the interaction, for example, an Orowan-related generation of a stress field around the particles could not be directly distinguished. The addition of the particles was obviously chosen in a range where an increase of the addition also led to a further increase of the hardness; therefore, no saturation conditions were reached.

The production of the AlN nanoparticles included a remaining contamination with pure $\mathrm{Al}$ [16]. In the case of Al-containing Mg alloys (like AM60 [6]) such effects will not be distinctly visible, but it requires a more fundamental analysis of the behavior in pure $\mathrm{Mg}$ or in $\mathrm{Al}-$ free $\mathrm{Mg}$ alloys. In Figure $2 \mathrm{~b}$, the presence of $\mathrm{Al}$ in absence of $\mathrm{N}$ confirms the formation of intermetallic compounds with $\mathrm{Al}$. In the case of ZW0303 the same was revealed with an additional content of Y. Furthermore, the small amount of $Y$ in solid solution was bound in particles, see Figure 2e. In the cast condition this was consistent with a further visible impact on the increase of the hardness. Accepting the increase of the hardness as a result of the AlN addition like in pure $\mathrm{Mg}$, it is also possible that a stabilization of second-phase particles with $\mathrm{Al}$ and $\mathrm{Y}$ added to increasing the hardness. Furthermore, the addition of AlN particles and the additional $\mathrm{Al}$ also resulted in the removal of solid solution $\mathrm{Y}$ from the matrix into the precipitates.

During extrusion, the addition of the nanoparticles contributed to a decrease of the recrystallized grain size of the extruded bars. As a direct particle effect on the recrystallization behavior, the interaction became especially clear in the smaller grain structures in the direct proximity of stringer-type alignments of precipitates. Grain boundary pinning [20] due to the particles interface can be hypothesized as the determining mechanism, while a particle stimulation of recrystallization would result in a similar result as well and easily correspond to stress fields generated by an Orowan strengthening mechanism. Nevertheless, the combination of grain refinement and particle-related strengthening resulted in a continuous increase of the hardness with the particle content, in fact only slightly more pronounced compared to the cast condition. This suggests that the particle alignment in the form of stringers did not change the strengthening tendency of the particles in pure magnesium. Although the texture itself will also distinctly influence the mechanical behavior, no impact is expected, as the texture variation with the addition of AlN is negligible. In ZW0303, the initial extremely fine-grained microstructure and the achieved high strain levels (high fracture strain in Figure $6 \mathrm{~b}, \mathrm{~d}$ ) corresponded to a texture which in part shows what is sometimes called a "rare earth" component with a tilt of basal planes out of the alignment along the extrusion direction. This specific aspect was not maintained after the addition of the AlN particles and corresponded to the significant increase of the average grain size. In earlier work, a retardation of grain boundary mobility [20] during recrystallization has been revealed to explain the occurrence of such microstructures and textures, as well as a particle-related boundary pinning. In the present case, solute $Y$ was removed from the material matrix during the addition of AlN, and it was bound in additional particles of various types concurrent to the AlN-particles. This removal was consistent with the complete change of the microstructure development, leading to grain coarsening and a drop in the hardness due to the ability of the material to recrystallize in the absence of solute $Y$ but not the particles. Thus, it can be hypothesized that the microstructure effect of the $Y$ addition in earlier works is more clearly related to solute $Y$ but not significantly to a particle effect. Only if the AlN addition is high, it may be concluded that a slight decrease of the grain size reveals the same effect of the particles as in pure Mg. Furthermore, the grain size-related decrease of the hardness is then followed by an increase concurrent to the further addition of AlN particles.

Generally, the fundamental difference between the stress-strain diagrams in tension and compression were related to the texture of the material $[7,21]$. The underlying alignment of basal planes 
parallel to the extrusion direction resulted in a slip-dominated flow in tension but a twin-dominated flow in compression. The following strain hardening behavior in tension with an increase of stress during straining but at a decreasing rate (i.e., the slope decreased) is consistent with the interaction of various slip modes. However, in compression, twinning is preferred and leads to a substantial decrease of the yield point, compared to tension, as well as to an S-shaped strain hardening behavior. The first increase of the slope of the stress-strain diagram was associated with the addition of twin boundaries as obstacles for material flow and the decrease of the slope after reaching an inflection point with reaching a fully twinned condition of the material [22]. It becomes clear in Figure 6a,c that there is no substantial change of such flow behavior in tension and in compression for pure $\mathrm{Mg}$, and thus, the dominating deformation mechanisms were not influenced by the addition of AlN particles. Only a shift of the stress levels towards higher values was continuously revealed in both tension and compression tests. In the case of ZW0303, a hardness drop was found concurrent to a distinct coarsening of the microstructure after extrusion, which is the opposite of the effect the AlN particle addition had in the case of pure $\mathrm{Mg}$ which is correlated to the corresponding grain coarsening with the addition of AlN.

While a distinct change in the strain hardening behavior of ZW0303 in tension was also found with the initial addition of AlN particles, the same was not as strongly expressed in compression. The further addition of the particles again did not specifically change the mechanical behavior, while shifting stress levels upward to some extent.

\section{Conclusions}

Two nanocomposite materials based on magnesium were studied after casting and indirect extrusion. Mg and ZW0303 with varying contents of AlN nanoparticles, respectively, were used to examine the effect of the AlN nanoparticles on the microstructure, the texture, and the mechanical properties.

As a sole effect of the addition of AlN particles, a small increase in the stress properties was revealed in pure $\mathrm{Mg}$ as well as in ZW0303. This increase was clearly visible in the cast condition of the samples, and in the case of pure Mg it was directly transferred into the extruded condition of the samples, where grain refinement was also observed.

For ZW0303, the same tendency was revealed if the sole effect of the particles was selected. Furthermore, an Al contamination and a concurrent removal of $Y$ as a solute element of the matrix underlined the importance of this element for the mechanical behavior (especially the ductility of the material) and confirmed an effect of solute drag of grain boundary mobility during recrystallization, whereas a particle-related effect was not confirmed. Furthermore, the concurrent grain size effect had a more significant impact on the strength properties compared to the added nanoparticles.

Author Contributions: D.G. contributed extrusion, mechanical characterization, metallography, texture evaluation and microstructure analysis; J.B. contributed extrusion and texture evaluation and calculation of pole figures; H.D. contributed casting and chemical analysis; J.B. and H.D. contributed idea of the paper and coordination of the authors.

Acknowledgments: The authors wish to acknowledge Alexander Vorozhtsov from Tomsk State University for supplying AlN nanoparticles.

Conflicts of Interest: The authors declare no conflict of interest.

\section{References}

1. Gupta, M. Magnesium-based nanocomposites: Lightweight materials of the future. Mat. Charact. 2015, 105, 30-46. [CrossRef]

2. Casati, R. Metal matrix composites reinforced by nano-particles-A review. Metals 2014, 4, 65-83. [CrossRef]

3. Jayakumar, J. Recent development and challenges in synthesis of magnesium matrix nano composites-A review. Int. J. Latest Res. Sci. Technol. 2012, 12, 164-171.

4. Dieringa, H. Properties of magnesium alloys reinforced with nanoparticles and carbon nanotubes: A review. J. Mat. Sci. 2011, 46, 289-306. [CrossRef] 
5. Dieringa, H. Processing of magnesium-based metal matrix nanocomposites by ultrasound-assisted particle dispersion: A review. Metals 2018, 8, 431. [CrossRef]

6. Dieringa, H.; Katsarou, L.; Buzolin, R.; Szakács, G.; Horstmann, M.; Wolff, M.; Mendis, C.; Vorozhtsov, S.; StJohn, D. Ultrasound assisted casting of an AM60 based metal matrix nanocomposite, its properties, and recyclability. Metals 2017, 7, 388. [CrossRef]

7. Bohlen, J.; Dobroň, P.; Swiostek, J.; Letzig, D.; Chmelík, F.; Lukáč, P.; Kainer, K.U. On the influence of the grain size and solute content on the AE response of magnesium alloys tested in tension and compression. Mater. Sci. Eng. 2007, 462, 302-306. [CrossRef]

8. Victoria-Hernández, J.; Hernández-Silva, D.; Yi, S.B.; Letzig, D.; Bohlen, J. Intermediate temperature deformation behaviour of fine grained AZ61 alloy processed by hydrostatic extrusion. Mater. Sci. Eng. 2011, 530, 411-417. [CrossRef]

9. Barnett, M.R. Forming of magnesium and its alloys. In Fundamentals of Magnesium Alloy Metallurgy, 1st ed.; Pekguleryuz, M.O., Kainer, K.U., Kaya, A.A., Eds.; Woodhead Publishing Ltd.: Cambridge, UK, 2013; pp. 197-231.

10. Nie, K.B.; Wang, X.J.; Xu, L.; Wu, K.; Hu, X.S.; Zheng, M.Y. Effect of hot extrusion on microstructures and mechanical properties of $\mathrm{SiC}$ nanoparticles reinforced magnesium matrix composite. J. Alloys Compd. 2012, 512, 355-360. [CrossRef]

11. Chen, Y.; Tekumalla, S.; Guo, Y.B.; Gupta, M. Introducing Mg-4Zn-3Gd-1Ca/ZnO nanocomposite with compressive strengths matching/exceeding that of mild steel. Sci. Rep. 2016, 6, 32395. [CrossRef] [PubMed]

12. Stanford, N.; Barnett, M.R. The origin of "rare earth" texture development in extruded Mg-based alloys and its effect on tensile ductility. Mater. Sci. Eng. 2013, 565, 459-468. [CrossRef]

13. Bohlen, J.; Yi, S.; Letzig, D.; Kainer, K.U. Effect of rare earth elements on the microstructure and texture development in magnesium-manganese alloys during extrusion. Mater. Sci. Eng. 2010, 527, 7092-7098. [CrossRef]

14. Kwak, T.Y.; Kim, W.J. Mecahnical properties and Hall-Petch relationship of the extruded Mg-Zn-Y alloys with different volume fraction of icosahedral phase. J. Alloys Compd. 2019, 770, 589-599. [CrossRef]

15. Chino, Y.; Sessa, K.; Mabuchi, M. Texture and stretch formability of a rolled Mg-Zn alloy containing dilute content of Y. Mater. Sci. Eng. 2009, 513, 394-400. [CrossRef]

16. Lerner, M.I.; Glazkova, E.A.; Lozhkomoev, A.S.; Svarovskaya, N.V.; Bakina, O.V.; Pervikov, A.V.; Psakhie, S.G. Synthesis of $\mathrm{Al}$ nanoparticles and $\mathrm{Al} / \mathrm{AlN}$ composite nanoparticles by electrical explosion of aluminum wires in argon and nitrogen. Powder Technol. 2016, 295, 307-314. [CrossRef]

17. Bachmann, F.; Hielscher, R.; Schaeben, H. Texture analysis with MTEX-Free and open source software toolbox. Solid State Phenom. 2010, 160, 63-68. [CrossRef]

18. Yi, S.; Brokmeier, H.G.; Letzig, D. Microstructural evolution during the annealing of an extruded AZ31 magnesium alloy. J. Alloys Compd. 2010, 506, 364-371. [CrossRef]

19. Christian, J.W.; Mahajan, S. Deformation twinning. Prog. Mater Sci. 1995, 39, 1-157. [CrossRef]

20. Hadorn, J.P.; Hantzsche, K.; Yi, S.; Bohlen, J.; Letzig, D.; Wollmershauser, J.A.; Agnew, S.R. Role of solute in the texture modification during hot deformation of Mg-rare earth alloys. Metall. Mater. Trans. 2012, 43, 1347-1362. [CrossRef]

21. Barnett, M.R. Twinning and its role in wrought magnesium alloys. In Advances in Wrought Magnesium Alloys; Bettles, C., Barnett, M.R., Eds.; Woodhead Publishing: Cambridge, UK, 2012; pp. 105-136.

22. Dobron, P.; Chmelık, F.; Yi, S.; Parfenenko, K.; Letzig, D.; Bohlen, J. Grain size effects on deformation twinning in an extruded magnesium alloy tested in compression. Scr. Mater. 2011, 65, 424-427. [CrossRef]

(C) 2019 by the authors. Licensee MDPI, Basel, Switzerland. This article is an open access article distributed under the terms and conditions of the Creative Commons Attribution (CC BY) license (http://creativecommons.org/licenses/by/4.0/). 